\title{
Produção científica da enfermagem fundamentada em educação popular
}

\author{
Scientific production of nursing based on popular education \\ Producción científica de la enfermería fundamentada en educación popular
}

\author{
ISES ADRIANA REIS DOS SANTOS ${ }^{1}$; MARIA do ESPIRITO SANTO DA SILVA ${ }^{2}$; LAZARO SoUZA \\ DA SILVA ${ }^{3}$; ROSANA MARIA DE OLIVEIRA SILVA ${ }^{4}$; GILbERTO TADEU REIS DA SILVA ${ }^{5}$; \\ Albertina Clemente Santana ${ }^{6}$; Rochelle Cintia Militão Maciel Carneiro ${ }^{7}$ \\ UNIVERSIDAdE FEDERAL DA BAHIA, UFBA, SALVADOR-BA, BRASIL \\ FaCUldade Maria Milza, FAMAM, Governador MANGABEIRA -BA, Brasil
}

\begin{abstract}
RESUMO
Objetivou-se caracterizar a produção científica fundamentada no referencial teórico da Educação Popular advinda dos programas de pós-graduação stricto sensu em Enfermagem, a partir de estudo bibliométrico realizado nos principais bancos de dados de teses e dissertações do Brasil. Foram analisadas as produções publicadas de 2007 a 2016, disponíveis em versão eletrônica, e selecionados 15 estudos: 4 teses e 11 dissertações, o que demonstrou a incipiência da produção científica sobre a temática pela enfermagem. Considera-se importante prover meios que possibilitem novos estudos com abordagem de acordo com orientações da Política Nacional da Educação Popular em Saúde, no âmbito do Sistema Único de Saúde brasileiro.
\end{abstract}

Palavras-chave: Educação. Enfermagem. Saúde. Produção Científica em Programas de Pós-Graduação.

\begin{abstract}
It aimed to characterize the scientific production based on the theoretical reference of the Popular Education coming from the graduate programs, in the modal stricto sensu in Nursing. Bibliometric study, carried out in the main databases of theses and dissertations. Analyzed the productions published from 2007 to 2016, available in electronic version, and selected 15 studies: 4 theses and 11 dissertations. It was verified the incipience of the scientific production on the subject by the nursing, being important to provide means that allow new studies with approach according to guidelines of the National Policy of Popular Education in Health, within the scope of the Unified Health System.
\end{abstract}

Keywords: Education. Nursing. Health. Scientific Production in Graduate Programs.

\section{RESUMEN}

Objetivó caracterizar la producción científica fundamentada en el referencial teórico de la Educación Popular proveniente de los programas de postgrado, en la modalidad stricto sensu en Enfermería. Estudio bibliométrico, realizado en los principales bancos de datos de tesis y disertaciones. Se analizaron las producciones publicadas de 2007 a 2016, disponibles en versión electrónica, y seleccionados 15 estudios: 4 tesis y 11 disertaciones, lo que demostró la escasa producción científica sobre la temática por la enfermería. Se considera importante proveer medios que posibiliten nuevos estudios con abordaje de acuerdo con orientaciones de la Política Nacional de la Educación Popular en Salud, en el ámbito del Sistema Único de Salud brasileño.

Palabras clave: Educación. Enfermería. Salud. Producción Científica en Programas de Postgrado.

\footnotetext{
1 Mestranda em Enfermagem e Saúde (PPGENF/UFBA). Integrante do Grupo de Estudos e Pesquisa em Administração dos Serviços de Enfermagem (GEPASE). E-mail: ises.adriana.reis@ gmail.com

${ }^{2}$ Docente da FAMAM. Mestre em Enfermagem e Saúde (PPGENF/UFBA). Integrante do GEPASE. E-mail: mariadoespirito@gmail.com

${ }^{3}$ Doutorando em Enfermagem (PPGENF/UFBA). Integrante do GEPASE. E-mail: lazo_1ss@ hotmail.com

${ }^{4}$ Professora Associada I da Escola de Enfermagem da UFBA (EEUFBA). Vice-líder do GEPASE. E-mail: rosanaosilva@hotmail.com

${ }^{5}$ Professor Titular EEUFBA. Líder do GEPASE. E-mail: gilberto.tadeu@ufba.br

${ }^{6}$ Enfermeira do Complexo Hospitalar Universitário Professor Edgard Santos (HUPES/UFBA). Especialista em Saúde Pública com ênfase em PSF e Auditoria de Sistemas de Saúde. E-mail: albertinaclemente@ yahoo.com.br

${ }^{7}$ Enfermeira do HUPES/UFBA. Especialista em Enfermagem Neonatal. E-mail: rochellecintia@ hotmail.com
} 
Ises A. R. Santos; Maria E. S. Silva; Lazaro S. Silva; Rosana M. O. Silva; Gilberto T. R. Silva; Albertina C. Santana; Rochelle C. M. M. Carneiro

\section{INTRODUÇÃOO}

A Educação Popular (EP) enquanto fundamentação teórica é reconhecida como um modelo de transformação social com vistas à libertação e emancipação, com princípio de educar de modo a valorizar o conhecimento do povo e as diferentes realidades culturais, na promoção de mudanças por meio da participação popular e na construção de novos conhecimentos.

Trata-se de uma leitura da realidade sob a ótica do oprimido, iniciada no século XX na América Latina, a partir das lutas de determinados grupos por igualdade de ideias, transformação e inovação (STRECK; ADAMS, 2012; MORETTI; ADAMS, 2011), utilizando o saber popular como matéria-prima para o ensino e libertação resultando na construção de novos saberes com base num conhecimento preexistente, experienciado e compartilhado entre pessoas de uma mesma comunidade.

Nesse sentido, cabe mencionar a participação de intelectuais orgânicos na área da saúde como o educador Paulo Freire e Victor Valla, principais incentivadores dos enfrentamentos das desigualdades sociais no País (BRASIL, 2013; STOLTZ, 2009), que através de suas reflexões contribuíram ativamente para uma formação de educadores e profissionais da área da saúde orientados pela compreensão dos comportamentos sociais. Participantes na construção de ações em conjunto com as classes populares, associadas às práticas populares do cuidado advindas das histórias de superações vivenciadas pela comunidade de forma integrada e compartilhada dos saberes (BRASIL, 2014; BARATA; BRICEÑO-LEÓN, 2000).

Está articulada com premissas éticas e estratégias de promoção para a formação de profissionais voltados para as reais necessidades da população em prol da valorização das práticas populares de saúde e da participação popular em atendimento aos princípios e fortalecimento do Sistema Único de Saúde (SUS) (BRASIL, 2009; STOLTZ; DAVID; WONG UN, 2005). Possibilita o estabelecimento de um processo de mobilização política e participativa a partir dos movimentos sociais no intuito de resgatar a cultura e a afirmação das pessoas, ferramentas indispensáveis para a construção da Política Nacional de Educação Popular em Saúde no âmbito do SUS (PNEPS-SUS) instituída em 2013, por meio da portaria n. 2.761 (AMARAL; PONTES; SILVA, 2014; BRASIL, 2013).

Nesse contexto, a abordagem fundamentada no referencial teórico da Educação Popular em saúde, significa um instrumento que reorienta a globalidade das práticas executadas, por proporcionar a superação do aspecto meramente biológico, do autoritarismo intelectual, do desprezo pelas iniciativas dos populares e da imposição de soluções técnicas restritas para problemas sociais globais, orientada pelos diálogos com os movimentos sociais associados às práticas populares.

$\mathrm{O}$ crescente diálogo entre os diversos atores fomenta discussões acerca das reais necessidades de saúde da população e tem como consequência o desenvolvimento de programas e políticas sociais e de saúde que concebem o indivíduo como um ser único, integral e parte de um coletivo que possui e deve ter contempladas suas especificidades, num contexto de vulnerabilidades (AMARAL; PONTES; SILVA, 2014; DAVID; BONETTI; SILVA, 2012).

Diante do exposto, o desenvolvimento deste estudo foi motivado pela relevância do tema e pelo envolvimento de seus autores com a realização de práticas educativas em serviços de saúde no âmbito do SUS e, principalmente, considerando suas participações no Programa de Pós-Graduação da Universidade Federal da Bahia (UFBA), o que 
permitiu trazer esta temática para sala de aula e ampliar o interesse por melhor investigá-la.

Sendo assim, optou-se pela seguinte questão norteadora: Como se caracteriza a produção científica fundamentada no referencial teórico da Educação Popular advinda dos programas de pós-graduação, na modalidade stricto sensu em Enfermagem? Para responder a tal questionamento, definiu-se o objetivo de caracterizar essa produção científica, por entender que a relevância deste estudo reside na busca por identificar de que forma estes trabalhos estão sendo desenvolvidos e sua importância para a comunidade.

\section{METODOLOGIA}

Foi realizado um estudo bibliométrico, por meio da análise de produções disponíveis no Banco de Dados de Teses e Dissertações do Centro de Aperfeiçoamento de Pessoal de Nível Superior (BTD CAPES), na Biblioteca Digital do Instituto Brasileiro de Informação em Ciência e Tecnologia (BDTD IBICT) e nos Catálogos do Centro de Estudos e Pesquisas em Enfermagem (CEPEn) da Associação Brasileira de Enfermagem (ABEn), publicados no período de 2007 a 2016, com acesso eletrônico.

Adotou-se este período temporal tendo em vista o marco legal da Instituição da Política Nacional da Educação Popular em Saúde no âmbito do Sistema Único de Saúde (PNEPS-SUS) (BRASIL, 2013).

A coleta dos dados ocorreu no período de 26 de julho a 13 de setembro de 2017, utilizando-se a estratégia de busca Educação Popular OR Educação Popular em Saúde AND Enfermagem e a palavra-chave "educação popular em enfermagem". Não foram utilizados descritores indexados, por não serem adotados nos catálogos publicados pelo CEPEn até 2010.

Estabeleceu-se, como critério de inclusão, a utilização do termo educação popular nos resumos das teses e dissertações. Excluíram-se estudos em duplicidade e aqueles que não correspondiam à área de Enfermagem e/ou à temática proposta para esta investigação.

No período analisado, foram identificadas $9.297^{8}$ produções na área de conhecimento de Enfermagem, das quais apenas 23 tinham sido desenvolvidas segundo os fundamentos do referencial teórico da Educação Popular. No entanto, após aplicação dos critérios de inclusão e exclusão, fez-se a seleção de 15 trabalhos.

Após a coleta, os dados foram organizados em planilhas no Microsoft Office Excel® 2010 para preenchimento de um instrumento previamente elaborado, composto pelas variáveis: Instituição de defesa, ano de publicação, autor, grau acadêmico, orientador, área de concentração, objetivos, projeto de pesquisa, linha de pesquisa.

De posse dos dados e informações atinentes ao quantitativo e à distribuição das produções com a referida abordagem temática, realizaram-se a caracterização e discussão dos achados.

\footnotetext{
${ }^{8} 44$ na base IBICT; 9.244 na base CAPES; 9 na base CEPEn.
} 
Ises A. R. Santos; Maria E. S. Silva; Lazaro S. Silva; Rosana M. O. Silva; Gilberto T. R. Silva; Albertina C. Santana; Rochelle C. M. M. Carneiro

\section{RESUltados}

Conforme demonstrado no Gráfico 1, o ano com maior número de publicações de teses e dissertações foi o ano de 2016, e em relação à temática a maior publicação aconteceu no ano de 2015 com 4 publicação em um total de 15.

Gráfico 1 - Quantitativo de trabalhos publicados nas bases de dados segundo Fundamentos do Referencial Teórico em Educação Popular pela Enfermagem e ano de publicação.

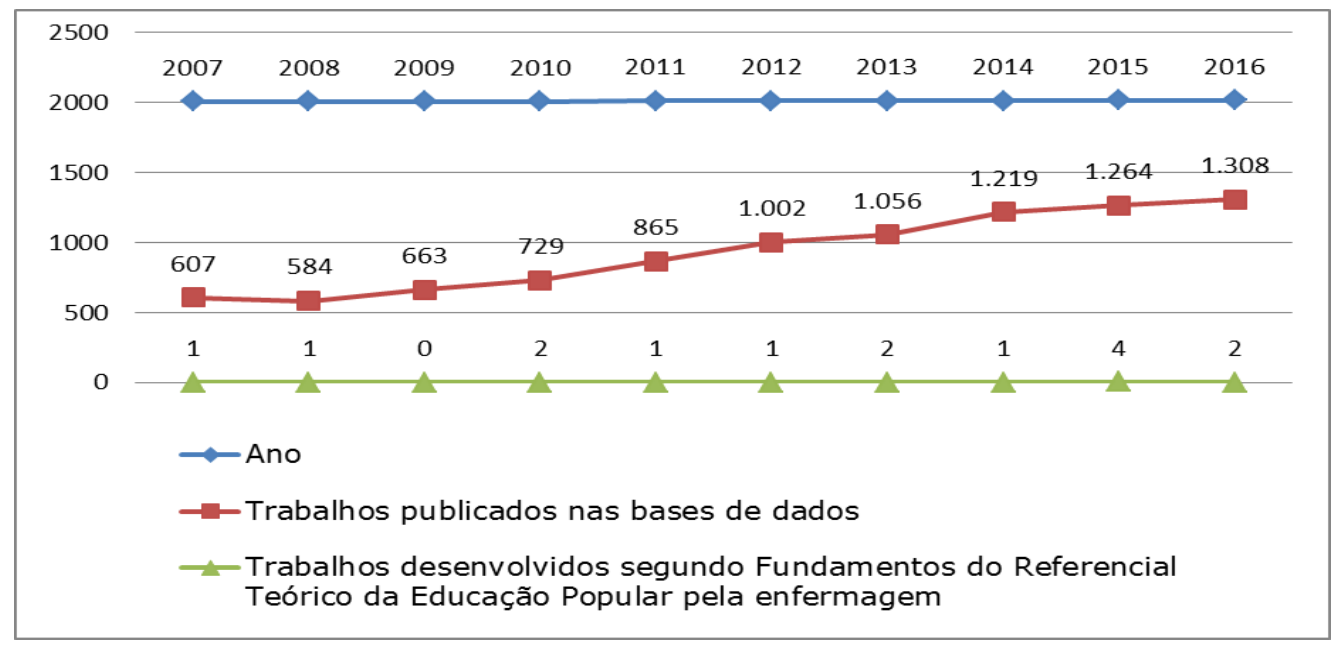

Fonte: Dados da pesquisa.

A Tabela 1 demonstra o quantitativo de produções de acordo com a Instituição de defesa, ressaltando-se uma concentração maior nos Estados de São Paulo e Rio de Janeiro representando um percentual total de $73 \%$.

Evidenciou-se que as Instituições com maior número de defesas na temática foram a USP com 3 teses e 2 dissertações, a UERJ e UFF totalizando 4 dissertações. Em relação ao Programa de Pós-Graduação houve maior número de trabalhos produzidos durante o mestrado.

Tabela 1 - Número de produções científicas segundo Instituição de Defesa, Unidade Federativa e Programas de Pós-Graduação (2007-2016).

\begin{tabular}{|c|c|c|c|c|}
\hline \multirow[t]{2}{*}{ Instituição de defesa - UF } & \multicolumn{2}{|c|}{$\begin{array}{l}\text { Programa de Pós- } \\
\text { Graduação }\end{array}$} & \multirow[t]{2}{*}{$\mathbf{N}$} & \multirow[t]{2}{*}{$\%$} \\
\hline & Doutorado & Mestrado & & \\
\hline Universidade de São Paulo / USP - SP & 3 & 2 & 5 & $33 \%$ \\
\hline Universidade Federal Fluminense / UFF - RJ & - & 2 & & \\
\hline $\begin{array}{l}\text { Universidade do Estado do Rio de Janeiro / UERJ - } \\
\text { RJ }\end{array}$ & - & 2 & 6 & $40 \%$ \\
\hline $\begin{array}{l}\text { Universidade Federal do Rio de Janeiro / UFRJ - } \\
\text { RJ }\end{array}$ & 1 & 1 & & \\
\hline $\begin{array}{l}\text { Universidade Federal de Mato Grosso / UFMT - } \\
\text { MG }\end{array}$ & - & 1 & & \\
\hline $\begin{array}{l}\text { Universidade Federal do Rio Grande do Sul / } \\
\text { UFRS - RS }\end{array}$ & - & 1 & 4 & $27 \%$ \\
\hline $\begin{array}{l}\text { Faculdade de Ciências Médicas da Universidade } \\
\text { Estadual de Campinas / UNICAMP - SP }\end{array}$ & - & 1 & & \\
\hline Universidade Federal do Rio Grande / FURG - RG & - & 1 & & \\
\hline $\begin{array}{ll} & \text { Total } \\
& \end{array}$ & 4 & 11 & 15 & $100 \%$ \\
\hline
\end{tabular}

Fonte: Dados da pesquisa. 
Após a seleção e leitura dos resumos foi realizada a caracterização das produções iniciando a análise dos dados destacados no Quadro 1.

Quadro 1 - Caracterização da distribuição das produções científicas da área de Enfermagem conduzidas segundo a fundamentação teórica da Educação Popular (2007-2016).

\begin{tabular}{|c|c|c|c|c|c|}
\hline Local & Autor/Ano & Grau & Orientador/Área & Objetivos & $\begin{array}{l}\text { Projeto de pesquisa } \\
\text { (Linha de pesquisa) }\end{array}$ \\
\hline \multirow{5}{*}{$\begin{array}{c}\text { USP } \\
\text { São Paulo }\end{array}$} & $\begin{array}{c}\text { Daniel Teles } \\
2016\end{array}$ & Mestrado & $\begin{array}{l}\text { Maria de La O. } \\
\text { Ramallo } \\
\text { Cuidado e saúde }\end{array}$ & $\begin{array}{l}\text { Avaliar o efeito de uma } \\
\text { atividade educativa sobre } \\
\text { os conhecimentos e } \\
\text { práticas dos familiares de } \\
\text { lactentes, relativos à } \\
\text { promoção } \\
\text { desenvolvimento infantil } \\
\text { por meio do brincar. }\end{array}$ & $\begin{array}{l}\text { A educação em saúde na } \\
\text { promoção } \\
\text { desenvolvimento } \\
\text { criança. } \\
\text { (Processo saúde-doença de } \\
\text { indivíduos, famílias, } \\
\text { grupos sociais } \\
\text { coletividade). }\end{array}$ \\
\hline & $\begin{array}{c}\text { Rayla Amaral } \\
2015\end{array}$ & Doutorado & $\begin{array}{l}\text { Maria de La O. } \\
\text { Ramallo } \\
\text { Cuidado e saúde }\end{array}$ & $\begin{array}{l}\text { Sistematizar as bases } \\
\text { teóricas e operacionais do } \\
\text { cuidado à criança nascida } \\
\text { prematura, compor e } \\
\text { validar material de } \\
\text { educação em saúde para a } \\
\text { promoção de seu } \\
\text { desenvolvimento } \\
\text { funcional. }\end{array}$ & $\begin{array}{l}\text { Promoção do } \\
\text { desenvolvimento: uma } \\
\text { proposta de prática. } \\
\text { (Práticas, saberes } \\
\text { políticas de saúde). }\end{array}$ \\
\hline & $\begin{array}{c}\text { Fabricio José } \\
\text { Souza Bastos } \\
2014\end{array}$ & \multirow[t]{2}{*}{ Doutorado } & $\begin{array}{c}\text { Pedro Fredemir } \\
\text { Palha } \\
\text { Enfermagem em } \\
\text { saúde pública }\end{array}$ & $\begin{array}{l}\text { Analisar o processo de } \\
\text { tomada de decisão dos } \\
\text { profissionais de saúde no } \\
\text { SAMU e sua relação com a } \\
\text { produção de cuidado. }\end{array}$ & $\begin{array}{l}\text { Avaliação da atenção } \\
\text { básica para o tratamento da } \\
\text { tuberculose na perspectiva } \\
\text { dos profissionais de saúde } \\
\text { e doentes em municípios } \\
\text { do Brasil. } \\
\text { (Práticas, saberes } \\
\text { políticas de saúde). }\end{array}$ \\
\hline & $\begin{array}{l}\text { Iara Cristina } \\
\text { Pereira } \\
2016\end{array}$ & & \multirow{2}{*}{$\begin{array}{c}\text { Maria Amélia de } \\
\text { Campos Oliveira } \\
\text { Enfermagem em } \\
\text { saúde coletiva }\end{array}$} & $\begin{array}{l}\text { Identificar possibilidades e } \\
\text { limites no trabalho dos } \\
\text { ACS para a realização de } \\
\text { ações de promoção da } \\
\text { saúde. }\end{array}$ & $\begin{array}{l}\text { Competência requerida } \\
\text { para a prática profissional } \\
\text { de enfermagem. } \\
\text { (Processo saúde-doença de } \\
\text { indivíduos, famílias, } \\
\text { grupos sociais } \\
\text { coletividade). }\end{array}$ \\
\hline & $\begin{array}{c}\text { Valéria Marli } \\
\text { Leonello } \\
2007\end{array}$ & Mestrado & & $\begin{array}{l}\text { Construir um perfil de } \\
\text { competências para ação } \\
\text { educativa da enfermeira } \\
\text { em seu processo de } \\
\text { trabalho assistencial, com } \\
\text { base na perspectiva dos } \\
\text { sujeitos implicados na } \\
\text { formação inicial em } \\
\text { enfermagem. }\end{array}$ & $\begin{array}{l}\text { Desenvolvimento de } \\
\text { competências para a ação } \\
\text { educativa da enfermeira. } \\
\text { (Não Identificado). }\end{array}$ \\
\hline \multirow[b]{2}{*}{$\begin{array}{l}\text { UFRJ } \\
\text { Rio de } \\
\text { Janeiro }\end{array}$} & $\begin{array}{l}\text { Adriana F. da } \\
\text { Cruz } \\
2015\end{array}$ & Mestrado & $\begin{array}{l}\text { Maria S. S. dos } \\
\quad \text { Santos } \\
\text { Enfermagem no } \\
\text { contexto social }\end{array}$ & $\begin{array}{l}\text { Identificar, no processo de } \\
\text { trabalho, as ações } \\
\text { educativas desenvolvidas } \\
\text { junto a gestantes na doação } \\
\text { de sangue de cordão } \\
\text { umbilical e placentário. }\end{array}$ & $\begin{array}{l}\text { Ação assistencial consulta } \\
\text { de enfermagem na vivência } \\
\text { de quem assiste e assina. } \\
\text { (Educação e saúde em } \\
\text { enfermagem). }\end{array}$ \\
\hline & $\begin{array}{l}\text { Kleyde } \\
\text { Ventura de } \\
\text { Souza } \\
2008\end{array}$ & Doutorado & $\begin{array}{l}\text { Maria A. R. } \\
\text { Tyrrel e Mariene } \\
\text { A. de Oliveira } \\
\text { Enfermagem }\end{array}$ & $\begin{array}{l}\text { Discutir a educação } \\
\text { popular como uma } \\
\text { estratégia capaz de } \\
\text { contribuir para ampliar as } \\
\text { perspectivas de conquista } \\
\text { dos direitos sexuais e } \\
\text { reprodutivos de mulheres } \\
\text { de classes populares. }\end{array}$ & (Não identificado). \\
\hline \multirow[t]{2}{*}{$\begin{array}{l}\text { UERJ } \\
\text { Rio de } \\
\text { Janeiro }\end{array}$} & $\begin{array}{l}\text { Ariene } \\
\text { Faleiro Luiz } \\
2013\end{array}$ & \multirow[t]{2}{*}{ Mestrado } & $\begin{array}{c}\text { Sônia A. Oliveira } \\
\text { Enfermagem, } \\
\text { saúde e } \\
\text { sociedade. }\end{array}$ & $\begin{array}{l}\text { Analisar a situação do } \\
\text { enfermeiro nas práticas } \\
\text { educativas na estratégia de } \\
\text { saúde da família } \\
\text { considerando os princípios } \\
\text { da educação popular e } \\
\text { saúde. }\end{array}$ & $\begin{array}{l}\text { Processo de formação e } \\
\text { práticas dos profissionais } \\
\text { de saúde na estratégia da } \\
\text { saúde da família. } \\
\text { (Saberes políticos e } \\
\text { práticas em saúde coletiva } \\
\text { e enfermagem). }\end{array}$ \\
\hline & $\begin{array}{c}\text { Olivia } \\
\text { Luciana dos } \\
\text { S. Silva } \\
2012\end{array}$ & & $\begin{array}{c}\text { Helena Maria S. } \\
\text { L. David } \\
\text { Saúde e } \\
\text { sociedade }\end{array}$ & $\begin{array}{l}\text { Estudar as experiências do } \\
\text { PVP do Rio de Janeiro à } \\
\text { luz dos conceitos da } \\
\text { educação popular e saúde. }\end{array}$ & $\begin{array}{l}\text { Vidas paralelas: ações } \\
\text { compartilhadas em cultura } \\
\text { e saúde do trabalhador. } \\
\text { (Não identificado). }\end{array}$ \\
\hline
\end{tabular}


Ises A. R. Santos; Maria E. S. Silva; Lazaro S. Silva; Rosana M. O. Silva; Gilberto T. R. Silva; Albertina C. Santana; Rochelle C. M. M. Carneiro

\begin{tabular}{|c|c|c|c|c|c|}
\hline \multirow[t]{2}{*}{$\begin{array}{c}\text { UFF } \\
\text { Rio de } \\
\text { Janeiro }\end{array}$} & $\begin{array}{l}\text { Amanda } \\
\text { Portugal } \\
\text { Moreira } \\
2015\end{array}$ & \multirow{6}{*}{ Mestrado } & \multirow{2}{*}{$\begin{array}{c}\text { Vera Maria } \\
\text { Saboia Zink } \\
\text { A complexidade } \\
\text { do cuidado em } \\
\text { enfermagem e } \\
\text { em saúde }\end{array}$} & $\begin{array}{l}\text { Descrever o conhecimento } \\
\text { de pescadores a respeito do } \\
\text { câncer de pele; Discutir a } \\
\text { repercussão da prática } \\
\text { educativa em saúde de } \\
\text { enfermeiras com essa } \\
\text { população no que tange a } \\
\text { prevenção do câncer de } \\
\text { pele do tipo não } \\
\text { melanoma. }\end{array}$ & $\begin{array}{l}\text { Percepção e comunicação } \\
\text { de riscos sociais e à saúde } \\
\text { associados ao uso abusivo } \\
\text { de álcool e outras drogas. } \\
\text { (Cuidados coletivos em } \\
\text { enfermagem). }\end{array}$ \\
\hline & $\begin{array}{l}\text { Crystiane R. } \\
\text { B. Ribeiro } \\
2013\end{array}$ & & & $\begin{array}{l}\text { Caracterizar as condições } \\
\text { de trabalho e saúde destes } \\
\text { pescadores; Discutir uma } \\
\text { proposta participativa de } \\
\text { cuidado em saúde. }\end{array}$ & $\begin{array}{l}\text { Percepção e comunicação } \\
\text { de riscos sociais e à saúde } \\
\text { associados ao uso abusivo } \\
\text { de álcool e outras drogas. } \\
\text { (Cuidados coletivos em } \\
\text { enfermagem). }\end{array}$ \\
\hline $\begin{array}{l}\text { UFMT } \\
\text { Mato } \\
\text { Grosso }\end{array}$ & $\begin{array}{l}\text { Fagner Luiz } \\
\text { Lemes Rojas } \\
\quad 2015\end{array}$ & & $\begin{array}{c}\text { Márcia dos Santos } \\
\text { Ferreira } \\
\text { Educação }\end{array}$ & $\begin{array}{l}\text { Expressar as apropriações } \\
\text { da EPS sob a perspectiva } \\
\text { dos enfermeiros de Cuiabá, } \\
\text { Mato Grosso. }\end{array}$ & $\begin{array}{l}\text { Formação de } \\
\text { humanos no nível de } \\
\text { mestrado e doutorados em } \\
\text { educação. } \\
\begin{array}{l}\text { Movimentos } \\
\text { política enciais, } \\
\text { popular). }\end{array} \\
\end{array}$ \\
\hline $\begin{array}{l}\text { FURG } \\
\text { Rio } \\
\text { Grande do } \\
\text { Sul }\end{array}$ & $\begin{array}{l}\text { Juliana } \\
\text { Acosta } \\
\text { Santorum } \\
2010\end{array}$ & & $\begin{array}{c}\text { Maria E. de } \\
\text { Carvalho Cestari. } \\
\text { Enfermagem e } \\
\text { saúde }\end{array}$ & $\begin{array}{lr}\text { Investigar } & \text { em } \\
\text { profundidade } & \text { o } \\
\text { desenvolvimento do curso } \\
\text { de extensão universitária, } \\
\text { saúde, educação e política: } \\
\text { práxis no SUS. }\end{array}$ & $\begin{array}{l}\text { Vivenciando a formação } \\
\text { universitária na práxis da } \\
\text { educação popular. } \\
\text { (Éticas. Educação e saúde). }\end{array}$ \\
\hline \multirow{2}{*}{$\begin{array}{c}\text { UFRS } \\
\text { Rio } \\
\text { Grande do } \\
\text { Sul }\end{array}$} & $\begin{array}{c}\text { Isaquiel } \\
\text { Macedo da } \\
\text { Rosa } \\
2011\end{array}$ & & $\begin{array}{l}\text { Dora Lúcia C. de } \\
\text { Oliveira } \\
\text { Não identificado }\end{array}$ & $\begin{array}{lr}\text { Analisar o modo como a } \\
\text { educação popular, no } \\
\text { cenário da } & \text { extensão } \\
\text { universitária, } & \text { pode } \\
\text { contribuir com } & \text { o } \\
\text { fortalecimento } & \text { da } \\
\text { integralidade na formação } \\
\text { em enfermagem. }\end{array}$ & $\begin{array}{l}\text { Cenários de promoção de } \\
\text { integralidade do cuidado } \\
\text { na formação } \\
\text { enfermagem. } \\
\text { (Não identificado). }\end{array}$ \\
\hline & $\begin{array}{l}\text { Maura } \\
\text { Cristiane S. } \\
\text { Figueira } \\
2010\end{array}$ & & $\begin{array}{l}\text { Eliete Maria Silva } \\
\text { Enfermagem e } \\
\text { trabalho }\end{array}$ & $\begin{array}{l}\text { Analisar os saberes e } \\
\text { práticas educativas de } \\
\text { enfermeiras no contexto } \\
\text { das unidades de saúde da } \\
\text { família em Santarém no } \\
\text { Paraná }\end{array}$ & $\begin{array}{l}\text { Participação e controle } \\
\text { social no SUS. } \\
\text { (Gerenciamento dos } \\
\text { serviços de saúde e de } \\
\text { enfermagem). }\end{array}$ \\
\hline
\end{tabular}

Fonte: Dados da pesquisa.

\section{DISCUSSÃo}

$\mathrm{Na}$ análise dos dados verificou-se a incipiência na produção científica fundamentada no referencial teórico da educação popular advinda dos programas de pós-graduação stricto sensu, com somente 15 estudos publicados em 10 anos e em seu maior número, dissertações de mestrado.

Observa-se que esse quantitativo de produções pela enfermagem representou apenas uma publicação anual com um significativo aumento em 2015, passando a quatro trabalhos, que pode estar relacionado ao tempo requerido para elaboração/conclusão destes estudos de cunho social.

Os resultados encontrados sinalizam para a existência de um maior número de programas stricto sensu em nível de mestrado acadêmico e mestrado profissional no Brasil, de acordo com o preconizado pelo MEC, inclusive na área da Enfermagem (CAPES, 2016), a qual apresenta crescente aumento da produção científica qualificada e com significativas contribuições ao processo de internacionalização da ciência brasileira (WOOD JUNIOR; COSTA, 2015; BRASIL, 2014; 2010). Evidenciam, também, um 
maior número de programas de pós-graduação no Sudeste e Sul em relação às demais regiões.

Quanto à utilização dos fundamentos do referencial teórico da Educação Popular, ainda existe carência de publicações, mas nota-se que este foi adotado em todas as produções selecionadas. Pode-se ressaltar que os autores se apropriaram das concepções pedagógicas preconizadas por Paulo Freire, as quais permearam a ação participativa e a aplicabilidade de suas ideias agregadas ao PNEPS-SUS (CHIARELLA et al., 2015; BRASIL, 2014), de maneira condizente com uma política educativa que prioriza a perspectiva do conhecimento dos atores envolvidos, dotados de distintos saberes, em prol da construção de novos conhecimentos e consequente transformação dessa realidade, afinal, em uma perspectiva de educação democrática freireana "[...] educador e educando têm conhecimentos e a relação entre eles é provocadora de novos conhecimentos" (BARRETO, 2004, p. 90).

Vale ressaltar a publicação de um trabalho de enfermagem produzido em 2015 na área de concentração da Educação, na linha de pesquisa Movimentos Sociais, Políticas e Educação Popular, sob a orientação da professora doutora Márcia dos Santos Ferreira, uma socióloga/antropóloga atuante na Educação Popular com projetos de pesquisa e extensão em andamento e participação em eventos relacionados à temática, que expressa uma expansão das linhas de investigação dos cursos de pós-graduação em geral (SANTOS; AZEVEDO, 2009), com consequente aumento das produções científicas desenvolvidas na área de Enfermagem e interesse pela temática.

Destacam-se também as linhas de pesquisa: Processo Saúde-Doença de Indivíduos, Famílias, Grupos Sociais e Coletividade; Práticas, Saberes e Políticas de Saúde e Cuidados Coletivos em Enfermagem, as quais apresentam um maior quantitativo de produções, tendo sido desenvolvidas, em sua maioria, por pesquisadores na Universidade de São Paulo (USP), instituição que agrega maior concentração de produções científicas, e no Estado do Rio de Janeiro. Em uma análise mais acurada, foi possível observar que a maioria das produções integra projetos de maior amplitude, o que remete à importância de aumento nos incentivos para a realização de pesquisas (UNICAMP, 2002), especificamente nesta temática, visto que demandam maior tempo e recursos financeiros para realização, conclusão e publicação, assim como para devolução à comunidade pesquisada.

\section{CONSIDERAÇÕES FINAIS}

O presente estudo possibilitou verificar que a produção científica conduzida segundo o fundamento do referencial teórico da Educação Popular é incipiente no que concerne à área do conhecimento da Enfermagem, expresso pelo ainda escasso número de produções científicas divulgadas no período de 2007 a 2016. Diante dos resultados, infere-se que a reduzida produção científica possa decorrer de fatores que interferem no processo de trabalho da categoria, assim como na interpretação do profissional quanto ao significado e à importância das vivências da própria comunidade (não permitindo a ressignificação dos saberes e consequentemente o aprendizado coletivo).

Neste contexto observa-se que há pouca valorização e incentivo à participação popular nas discussões e definições das ações a serem desenvolvidas para as comunidades usuárias do SUS, fundamental para o processo de emancipação desses atores.

Diante disto, faz-se necessário que o cotidiano do profissional enfermeiro nas comunidades esteja diretamente conectado à academia para: discutir e socializar sua 
Ises A. R. Santos; Maria E. S. Silva; Lazaro S. Silva; Rosana M. O. Silva; Gilberto T. R. Silva; Albertina C. Santana; Rochelle C. M. M. Carneiro

prática (no intuito de evidenciá-la por meio da elaboração de artigos); contribuir com o despertar de um novo conhecimento (gerado nas vivências da comunidade); fortalecer a integração entre ensino e prática; formar novas gerações sensíveis aos interesses da saúde coletiva.

Assim, é importante o desenvolvimento de novas pesquisas fundamentadas na prática da EP, visto que tais estudos envolvem o saber e os interesses da comunidade (usuários do serviço público de saúde) e podem favorecer o empoderamento desses atores, a partir da compreensão de que podem e devem deixar a condição de meros expectadores e assumir o papel de verdadeiros agentes de mudanças que tanto buscam no cotidiano. 


\section{REFERÊNCIAS}

AMARAL, M. C. S.; PONTES, A. G. V.; SILVA, J. V. O ensino de Educação Popular em Saúde para o SUS: experiência de articulação entre graduandos de enfermagem e Agentes Comunitários de Saúde. Interface (Botucatu), v. 18, supl. 2, p. 1547-1558, 2014.

BARATA, R. B.; BRICEÑO-LEÓN, R. E. (Orgs.). Doenças endêmicas: abordagens sociais, culturais e comportamentais. Rio de Janeiro: Editora FIOCRUZ, 2000.

BARRETO, V. Paulo Freire para educadores. 6. ed. São Paulo: Arte e Ciência, 2004.

BRASIL. Ministério da Saúde. Secretária de Gestão Estratégica e Participativa. II Caderno de educação popular em saúde. Brasília: Ministério da Saúde, 2014. Disponível em: <

http://bvsms.saude.gov.br/bvs/publicacoes/2_caderno_educacao_popular_saude.pdf >. Acesso em: 14 set. 2017.

BRASIL. Portaria No 2.761, de 19 de novembro de 2013: Institui a Política Nacional de Educação Popular em Saúde no âmbito do Sistema Único de Saúde. Brasília: MS, 2013. Disponível em: < http://bvsms.saude.gov.br/bvs/saudelegis/gm/2013/prt2761_19_11_2013.html >. Acesso em: 11 de set. 2017.

BRASIL. Ministério da Saúde. Plano Nacional de Educação para o Decênio 2011-2020. Brasília: MS, 2010. Disponível em: < http://fne.mec.gov.br/images/pdf/notas_tecnicas_pne_2011_2020.pdf >. Acesso em: 20 ago. 2017.

BRASIL. Ministério da Saúde. Política Nacional de Gestão Estratégica e Participativa no SUS. $\begin{array}{lcccc}\text { Brasília: } & \text { MS, } & \text { Disponível } & \text { em: } & < \\ \text { http://bvsms.saude.gov.br/bvs/publicacoes/politica estrategica participasus } & \text { 2ed.pdf } & \text { >. Acesso em: } & 20\end{array}$ ago. 2017.

CAPES. Coordenação de Aperfeiçoamento de Pessoal de Nível Superior. Documento de Área 2016. 2016. Disponível em: < http://www.capes.gov.br/component/content/article/44-avaliacao/4667$\underline{\text { enfermagem }}>$. Acesso em: 10 ago. 2017

CHIARElla, T.; BIVANCO-LIMA, D.; MOURA, J. C.; MARQUES, M. C. C.; MARSiGLIA, R. M. G. A Pedagogia de Paulo Freire e o Processo Ensino-Aprendizagem na Educação Médica. Revista Brasileira de Educação Médica, v. 39, n. 3, p. 418-425, set. 2015.

DAVID, H. M. S. L.; BONETTI, O. P.; SILVA, M. R. F. A enfermagem brasileira e a democratização da saúde: notas sobre a Política Nacional de Educação Popular em Saúde. Revista Brasileira de Enfermagem, v. 65, n. 1, p. 179-185, jan./fev. 2012.

MORETTI, C. Z.; ADAMS, T. Pesquisa participativa e educação popular: epistemologias do sul. Educação e Realidade, v. 36, n. 2, p. 447-463, maio/ago. 2011.

SANTOS, A. L. F.; AZEVEDO, J. M. L. A pós-graduação no Brasil, a pesquisa em educação e os estudos sobre a política educacional: os contornos da constituição de um campo acadêmico. Revista Brasileira de Educação, v. 14, n. 42, p. 534-550, set./dez. 2009.

STOLTZ, E. N.; DAVID, H. M. S. L.; WONG UM, J. A. Educação Popular e Saúde: trajetória, expressões e desafios de um movimento social. Revista APS, v.8, n.1, p. 49-60, jan./jun. 2005.

STOLTZ, E. Entre a academia e a rua: Victor Vincent Valla (1937-2009). Interface (Botucatu), v. 13, n. 31, p. 461-466, out./dez. 2009.

STRECK, D.; ADAMS, T. Pesquisa em educação: os movimentos sociais e a reconstrução epistemológica num contexto de colonialidade. Educação e Pesquisa, v. 38, n. 1, p. 243-258, jan./mar. 2012. 
Ises A. R. Santos; Maria E. S. Silva; Lazaro S. Silva; Rosana M. O. Silva; Gilberto T. R. Silva; Albertina C. Santana; Rochelle C. M. M. Carneiro

UNICAMP. Fórum de Reflexão Universitária. Desafios da pesquisa no Brasil: uma contribuição ao debate. São Paulo em Perspectiva, v.16, n.4, p. 15-23, out./dez. 2002.

WOOD JUNIOR, T.; COSTA, C. C. M. Avaliação do impacto da produção científica de programas selecionados de pós-graduação em Administração por meio do índice H. Revista de Administração, v. 50, n. 3, p. 325-337, jul./set. 2015.

Recebido em: 14 ago. 2018.

Aprovado em: 23 dez. 2018. 